\title{
Glutathione Enhancer Protects Some \\ Biochemical and Haematological Parameters from the Effect of Electromagnetic Field
}

\author{
E. A. Marzook and F. A. Marzook*
}

Biological Application Dept., Nuclear Research Centre (NRC) and "Labelled Compounds Dept., Hot Lab Centre (HLC),

Egyptian Atomic Energy Authority, Egypt.

7 HE PRESENT study was designed to study the effect of exposure to electromagnetic field (EMF), emitted from a cellular tower for mobile phone on some biochemical and haematological parameters in male albino rats and to evaluate of the possible protective role of the antioxidant glutathione enhancer on the studied parameters.

Three groups of rats were studied, the control (unexposed), the exposed and the treated exposed groups. Exposed groups were subjected to EMF at frequency of $900 \mathrm{MHz}$, with a peak power of about $60 \mathrm{~W}$, power density of $0.05 \mathrm{~mW} / \mathrm{cm}^{2}$ at the site of exposure for $24 \mathrm{~h} /$ day for 8 weeks, at the same time treated group was supplied with oral injection of glutathione enhancer three times weekly.

At the end of experiment, serum levels of thyroid stimulating hormone (TSH), calcium (Ca), uric acid, malondialdehyde (MDA) beside, the activity of lactate dehydrogenase (LDH) were measured also, some haematological parameters were estimated. Impairment of TSH and serum calcium was expressed by a decrease in serum levels of the exposed group. Meanwhile, serum level of MDA, uric acid and the activity of LDH were increased by exposure.

The haematological studies revealed that, exposure to electromagnetic spectrum induced significant reduction in red blood cell counts (RBC's), and haemoglobin concentration $(\mathrm{Hb})$, meanwhile reticulocyte count (Ret) was elevated.

The leucocyte counts (WBC's) and platelets count were not affected by exposure.

The study demonstrated that glutathione enhancer can attenuate the side effects of exposure to electromagnetic field.

Keywords: Electromagnetic radiation, biological parameters, antioxidants. 
The ever increasing use of cellular phones and the increasing number of associated base stations are becoming a widespread source of nonionizing electromagnetic radiation (Yurekli et al., 2006). Chronic exposure for electromagnetic frequency waves EMF changes in cellular physiology and biochemistry including biomolecules profile. The most affected biomolecules are protein, hormones, lipid peroxides, reactive oxygen species (ROS), balanced electrolytes and all cellular systems (Akdag et al., 2013 and Dutta et al., 2015).

The cell membrane is considered as the primary site for EMF interaction with cellular systems. The mobilization of cellular calcium ion $\left(\mathrm{Ca}^{2+}\right)$ by electromagnetic radiation is an important biological response in the regulation of cellular activities (CSIRO, 1994 and Levis et al., 2015). The study of Bergamaschi et al. (2004) revealed that EMF induced changes of trans-membrane Ca flux may lead to altered metabolism and/ or secretion of neurohormones including TSH. As a result of TSH perturbation, oxidative stress can be easily achieved especially in case of low TSH level and increased free T3 and T4 (Dutta et al., 2015 and Kesari et al., 2013).

Electrolytic imbalance disturbs the redox potential because $\mathrm{Ca}$ level maintain the redox homeostasis by participating in cell biochemical activities to capture free radical formation (Akdag et al., 2013). Accordingly thyroid related hormonal imbalance mediated $\mathrm{Ca}$ disturbance were found to increase oxidative stress components such as uric acid, MDA (Schwarz et al., 2012). MDA is one of thiobarbituric acid reactive substances (TBARS), which is considered the main end product of lipid peroxidation, liberated in case of excessive generation of free radicals and their interaction with polyunsaturated fatty acids (PUFAs). Uric acid is the major end product of purine metabolism specifically the catabolism of the purine nucleosides adenosine and guanosine (Alfred, 1994). Uric acid is an effective antioxidant which contributes in the protective mechanisms against oxygen radicals (Ames et al., 1981). The hematopoietic system, like all body systems, is susceptible to damage by radiation, the effects of radiation are dependent on the nature and quantity of radiant energy, the duration of exposure, and the mitotic rate of the exposed cell population. The high mitotic activity of the bone marrow makes it one of the most susceptible organ systems to the toxic effect of radiation (Brain, 1994). One of the constituents of erythrocytes is LDH, its serum elevation may be encountered in variety of disorders including Egypt. J. Rad. Sci. Applic., Vol. 29, No. 1-2 (2016) 
haemolytic anaemia (Brain, 1994). The toxicity of free radicals can be neutralized by free radical scavengers and by indirect antioxidants. Molecules which directly scavenge free radicals includes glutathione (Halliwell, 1999), which is an important antioxidant and is used as substrate for glutathione reductase and glutathione peroxidase (Matamoros et al., 2003). Some studies also demonstrated that antioxidants prevent oxidative stress or apoptosis caused by radiofrequency electromagnetic waves (RF-EMW) in animal tissues (Oktem et al., 2005 and Ozguner et al., 2006).

Hence, the current study was performed to shed some light on the health hazards associated with biochemical and physiological changes induced by exposure to electromagnetic waves of Mobile Base Station (MBS). In addition, the study of the possible protective effect of glutathione enhancer is considered against the effect of electromagnetic radiation.

\section{Material and Methods}

In this study twenty seven adult male albino rats (Rattus rattus), weighing about 130-160g were used. Animals were randomly arranged into three groups (9rats each) as follows: Control (unexposed) group, EMF exposed group, EMF exposed+ glutathione-treated group. Electromagnetic radiation was applied to exposed groups for 8 weeks. Rats were obtained from the animal house of the $\mathrm{NRC}$, housed in plastic cages, given standard rodents feed and tap water $a d$ libitum and kept under constant conditions.

Two animal groups were exposed to electromagnetic radiation emitted from a cellular tower (base station) for mobile phone constructed on a roof of a building in Cairo at frequency of $900 \mathrm{MHz}$, with a peak power of about $60 \mathrm{~W}$, power density of $0.05 \mathrm{~mW} / \mathrm{cm}^{2}$ at the site of exposure at a distance of 15 meters in front of the antenna, 24h/ day for 8 weeks. The field strength emitted by the tower was measured with isotopic probe specified for measuring high frequency and the compartment shaped to standard IEEE C95 (Institute of Electrical and Electronic Engineer), as described by El-Abiad ( 2002).

The treated group received glutathione enhancer suspension orally using a stomach tube three times/ week for two months during exposure to EMF. Glutathione Enhancer was obtained from International Business Establishment Co. (IBE Pharma) SPI (distributor Nova Pharm.,Egypt). Each tablet $(512.5 \mathrm{mg}$ ) contains 50ng glutathione, 50mg L-Cysteine, 100mg N-acetyl cysteine, 50mg

Egypt. J. Rad. Sci. Applic., Vol. 29, No. 1-2 (2016) 
L-methionine, 250mg vitamin $\mathrm{C}$ and $250 \mathrm{mcg}$ selenium. Each two tablets were dissolved in $102.5 \mathrm{ml}$ distilled water to obtain a concentration of $10 \mathrm{mg} / \mathrm{ml}$. suspension was given orally at a dose of $1 \mathrm{ml} / 100 \mathrm{~g}$ of body wt.

At the end of experiment (8weeks), animals were fasted overnight then transferred to the laboratory. Blood samples were collected by decapitation for laboratory assessment of the studied parameters. Part of the blood was used for biochemical analysis blood was allowed to clot at $37 \mathrm{C}^{\circ}$ for $30 \mathrm{~min}$, centrifuged for $10 \mathrm{~min}$ at 5000rpm and sera were separated and kept frozen at -20C until analysis. Activity of LDH was estimated by measuring the rate of NADH consumption spectrophotometrically which is proportional to LDH activity (Witt and Trendlenberg, 1982). Total Ca was estimated by using colorimetric method of Tietz (1970) and serum uric acid concentration was measured according to Fossati et al. (1980). MDA was estimated colorimetrically by determining TBARs (Draper and Hadley, 1991). Determination of serum TSH was according to the method of Sooes et al. (1984) using commercial kits from Immunotech.

Blood for haematological parameters was collected on anticoagulant; disodium ethylenediaminetetra-acetate (EDTA). Haematological measurements erythrocyte counts (RBC's), haemoglobin ( $\mathrm{Hb}$ ), leukocyte counts (WBC's), platelets count (Pt) and reticulocyte count (Ret) were estimated using automatic counter (Guyatt et al., 1992).

\section{Statistical analysis}

Data are presented as mean \pm S. D. and range (lower limit-upper limit), analysed by student's $t$-test and the level of significance was set at $p<0.05$.

\section{Results}

The effect of the exposure of male rats to EMF of MBS, Table 1. showed a significant increase in serum MDA $(2.6 \pm 0.3)$ as compared to control group $(1.6 \pm 0.2)$ and a significant decrease was noted in the exposed group supplied with glutathione (1.62 \pm 0.16$)$ as compared to the exposed one which did not receive glutathione.

Serum TSH and Ca exhibited an opposite trend of alteration among the experimental groups, as a function of EMR-exposure and glutathione treatment

Egypt. J. Rad. Sci. Applic., Vol. 29, No. 1-2 (2016) 
in comparison with control group. Where, TSH showed significant decrease in the exposed group $(1.11 \pm 0.04)$ as compared to control group $(1.15 \pm 0.02)$ and insignificant difference was observed in the exposed treated group (1.12 \pm 0.04$)$ when compared to control and exposed groups. The exposed group, also exhibited significant decrease in the level of serum $\mathrm{Ca}(8.9 \pm 0.9)$ than control $(10.13 \pm 0.26)$ and exposed treated groups $(9.7 \pm 0.63)$. The exposed treated group showed no significant difference compared to control. In contrast, the level of uric acid expressed a significant rise in exposed group (5.5 \pm 0.5$)$ as compared to control group (4.7 \pm 0.5$)$, whereas, significant decline was noted in exposed glutathione treated group $(4.9 \pm 0.4)$ compared to the exposed one. As regard to enzyme activity, the data in Table 1. revealed that exposure to EMR induced significant elevation in the activity of $\mathrm{LDH}(637.3 \pm 73.3)$ as compared to control group (444.3 \pm 48.8$)$. Treatment with glutathione exerted a significant decline in exposed group $(492.1 \pm 58.9)$ in comparison to the exposed group, while no significant difference was recorded compared to control.

TABLE 1. Effect of glutathione on serum MDA, TSH, uric acid, calcium and LDH on rats exposed to electromagnetic radiation of base station for 8weeks.

\begin{tabular}{|c|c|c|c|}
\hline Parameters & Control & Exposed & Exposed treated \\
\hline MDA (nmol/ ml) & $1.6 \pm 0.2 \mathbf{b}$ & $2.6 \pm 0.3 \mathbf{a}$ & $1.62 \pm 0.16 \mathbf{b}$ \\
(Range) & $(1.3-1.8)$ & $(2.2-3.1)$ & $(1.4-1.9)$ \\
\hline TSH ( $\mu \mathrm{u} / \mathrm{ml})$ & $1.15 \pm 0.02 \mathbf{a}$ & $1.11 \pm 0.04 \mathbf{b}$ & $1.12 \pm 0.04 \mathbf{a}, \mathbf{b}$ \\
(Range) & $(1.12-1.16)$ & $(1.1-1.13)$ & $(0.13-1.14)$ \\
\hline Uric acid (mg/ dl) & $4.7 \pm 0.5 \mathbf{b}$ & $5.5 \pm 0.5 \mathbf{a}$ & $4.9 \pm 0.4 \mathbf{b}$ \\
(Range) & $(4.12-5.3)$ & $(4.95-6.36)$ & $(4.29-5.35)$ \\
\hline Calcium (mg/ dl) & $10.13 \pm 0.26 \mathbf{a}$ & $\mathbf{8 . 9} \pm \mathbf{0 . 9 b}$ & $9.7 \pm 0.63 \mathbf{a}$ \\
(Range) & $(9.33-10.3)$ & $(7.14-9.84)$ & $(8.8-10.96)$ \\
\hline LDH (u/l) & $444.3 \pm 48.8 \mathbf{b}$ & $637.3 \pm 73.3 \mathbf{a}$ & $492.1 \pm 58.9 \mathbf{b}$ \\
(Range) & $(386-518)$ & $(533-726)$ & $(399-566)$ \\
\hline
\end{tabular}

-Data are expressed as means \pm S. D. for 9rats in each group.

-Values in the same raw with different letters $(a, b$ or $c)$ are significantly different.

-Means followed by the same letter ( $\mathrm{a}, \mathrm{b}$ or $\mathrm{c}$ ) are not significantly different.

-Range is expressed as lower limit and upper limit in each group.

Haematological parameters in rats exposed to electromagnetic radiation in Table 2. The data revealed that there was a significant decrease $(p<0.05)$ in mean

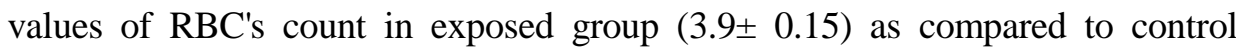
$(4.77 \pm 0.3)$ and the group exposed and treated with glutathione (4.5 \pm 0.3$)$ showing insignificant difference from the control group. Also mean value of haemoglobin concentration was significantly lower $(p<0.05)$ in exposed $(11.8 \pm$

Egypt. J. Rad. Sci. Applic., Vol. 29, No. 1-2 (2016) 
$0.5)$ as compared to the control (13.7 \pm 0.4$)$ and exposed treated groups (12.8 \pm 0.3 ). Meanwhile, $\mathrm{Hb}$ is still significantly decreased in exposed treated group when compared to control group. Contrary, mean value of reticulocyte count was significantly higher $(p<0.05)$ in exposed group $(1.3 \pm 0.3)$ as compared to control $(0.56 \pm 0.15)$ and exposed treated group $(0.86 \pm 0.15)$.

TABLE 2. Effect of glutathione on haematological parameters in rats exposed to electromagnetic radiation of base station for 8weeks.

\begin{tabular}{|c|c|c|c|}
\hline Parameters & Control & Exposed & Exposed treated \\
\hline RBC's $\left(\times 10^{6} / \mathrm{mm}^{3}\right)$ & $4.77 \pm 0.3 \mathbf{a}$ & $3.9 \pm 0.15 \mathbf{b}$ & $4.5 \pm 0.3 \mathbf{a}$ \\
$($ Range $)$ & $(4.3-5.2)$ & $(3.7-4.1)$ & $(4.2-5.0)$ \\
\hline Hb $(\mathrm{g} / \mathrm{dl})$ & $13.7 \pm 0.4 \mathbf{a}$ & $11.8 \pm 0.5 \mathbf{c}$ & $12.8 \pm 0.3 \mathbf{b}$ \\
$($ Range $)$ & $(12.9-14.1)$ & $(10.8-12.5)$ & $(12.3-13.3)$ \\
\hline WBC's $\left(10^{3} / \mathrm{mm}^{3}\right)$ & $9.2 \pm 0.4$ & $9.0 \pm 0.3$ & $9.0 \pm 0.3$ \\
$($ Range) & $(8.8-10.1)$ & $(8.7-9.5)$ & $(8.5-9.4)$ \\
\hline Ret $\left(10^{3} / \mathrm{mm}^{3}\right)$ & $0.56 \pm 0.15 \mathbf{c}$ & $1.3 \pm 0.3 \mathbf{a}$ & $0.86 \pm 0.15 \mathbf{b}$ \\
$($ Range $)$ & $(0.3-0.8)$ & $(0.9-1.8)$ & $(0.6-1.1)$ \\
\hline PLt $\left(10^{3}\right)$ & $186.8 \pm 9.1$ & $182 \pm 7.1$ & $187.4 \pm 8.2$ \\
$($ Range $)$ & $(176-200)$ & $(175-195)$ & $(176-197)$ \\
\hline
\end{tabular}

Legends as in Table 1.

Data showed no significant difference in total leucocytes and platelets count of studied groups as compared to the control group.

\section{Discussion}

The widespread use of the mobile phone has initiated many studies on the possible adverse effects of a high frequency EMF, emitted from mobile phones (Hata et al., 2005). As a tax of civilian life, electromagnetic field may induce biochemical and pathological alterations to the cell membrane, various enzymatic systems and electrolytic balanced components. Maganioti et al. (2010) mentioned that EMF induce the free radical pair mechanism in the cellular systems. The change includes excessive production of ROS, lipid peroxides and biomolecules such as uric acid a result of DNA breakdown. As the oxidative stress increased, there are expected high level of stress hormones T3 and T4 and disturbance of total electrolytes especially Ca concentration (Maganioti et al., 2010).

The remarkable reduction in serum $\mathrm{Ca}$ occurred with exposure can be explained by the effect of EMR which can increase ionized calcium uptake by skeleton, enhanced calcification and oesteogenesis in exposed animals. Results Egypt. J. Rad. Sci. Applic., Vol. 29, No. 1-2 (2016) 
are consistent with those of Bortkiewicz (2001) who attributed the effect of the electromagnetic field on the flow of ions across cell membranes. Also data are consistent with those of Persson et al. (1989) and Brovkovich et al. (1991) who reported that parasympathetic over activity during long term exposure to electromagnetic field released gastrocalcin that promoted the uptake of blood calcium into bone causing hypocalcaemia. Another data suggested that EMF induced opening of the calcium channel in the membrane rather than increase of the calcium mobilization from endoplasmic reticulum (Goodman et al., 1995). In general calcium profile disturbance mediated EMF can produce change in thyroid related hormones and oxidative stress.

TSH is secreted from the anterior pituitary gland and is controlled by thyroid hormones and thyrotorpin-releasing hormones. In the current study, the significant decrease in serum TSH in rats exposed to EMR as compared to that of control group can be attributed to the effect of EMF on the hypothalamic centres responsible for thyrotorpin-releasing hormones which become less sensitive to feedback inhibition by thyroid hormones. Several studies revealed that the activity of thyroid hormones increased by the effect of EMR (Adey, 1981, Dumanski1 et al., 1976 and Marzook, 2006). Accordingly, it can cause a decrease in TSH by feedback inhibition. Results are in accordance with those of Koyu et al. (2005) who found that $900 \mathrm{MHz}$ EMF emitted by cellular telephones decreases serum TSH levels. Meanwhile, results disagree with those of Djeridane et al. (2008) who revealed that TSH was not disturbed by RF-EMFs emitted by mobile phone Ahmedpoor et al. (2016).

Electromagnetic radiation or RF field of cellular mobile phones may affect biological systems by increasing free radicals, which appear mainly to enhance lipid peroxidation, by changing antioxidant defines systems of human tissues (Ozguner et al., 2005) and blood (Moustafa et al., 2001) leading to oxidative stress. Thus the significant increase in serum MDA in exposed group as compared to control one could be attributed to the overproduction of ROS due chronic exposure to EMR. Oxidative stress occurred as a consequence of imbalance between ROS and body antioxidant capacity (Ahmedpoor et al., 2009 and Yakymenko et al., 2014). This imbalance could happen as a result of increased ROS generation, impaired antioxidant defines system or their combination. It was found that electromagnetic radiation causes biological effect by increasing free radicals, which enhance lipid peroxidation, and by changing the antioxidant Egypt. J. Rad. Sci. Applic., Vol. 29, No. 1-2 (2016) 
defence system of human tissues, leading to oxidative stress (Ozguner et al., 2005 and Johanson, 2009). Results agree with those reported by Stopczyk et al. (2002) and Ilhan et al. (2004). A significant rise in MDA level in rats exposed to EMF indicated that those animals suffered from oxidative stress which was neutralized by the use of antioxidant glutathione. Results are also consistent with those of Ilhan et al. (2004) who found increased MDA level in brain tissue of rats exposed to $900 \mathrm{MHz}$ of MBS for seven days that was prevented by treatment with Ginko biloba and the improvement reported by Ozguner et al. (2005) after treatment caffeic acid phenyl ester.

The increased EMF induced oxidative stress may lead to increased T3 and T4 which in turn induces overproduction of uric acid (Hashem and El-Sharkawy, 2009). Hyperuricaemia may be caused by either increased production of uric acid or decreased renal excretion. Increased production is seen with increased nucleic acid turnover which leads to increased catabolism of purines which can be seen in rapid proliferation of cells as in lymphoproliferative disorder, malignancy or in haemolytic anaemia, primary gout and many other factors including radiation (Alfred, 1994). Thus, the significant alteration of serum uric level between control animals and EMR exposed group noted herein may be attributed to increased catabolism of purines or due to increased haemolysis caused by effect of electromagnetic radiation exposure in this study. Also increased uric acid may be a compensatory mechanism trying to counteract oxidative stress since uric acid is considered as antioxidant which contributes in the mechanism against oxygen radicals (Ames et al., 1981 and Hamed et al., 2004). Result was consistent with those described by Dasdag et al. (1999) who investigate the effects of RF and microwave (MW), non-ionizing radiation, and observed an increase serum uric acid. Improvement after treatment of exposed animals with glutathione could be attributed to increased TSH level accordingly decreased T3 and T4 as well as oxidative stress.

The blood integrity is a picture of normal blood picture and normal enzymatic profile like Lactate dehydrogenase. LDH is present in all body cells but its higher concentrations are found in liver, heart, kidney, skeletal muscle and erythrocytes. Total LDH-concentration in serum or plasma is increased in patients with liver disease, renal disease, myocardial infarction, many malignant diseases, progressive muscular dystrophy and almost any cause of haemolysis Egypt. J. Rad. Sci. Applic., Vol. 29, No. 1-2 (2016) 
(Friedman and Young, 2001). The results obtained revealed that the activity of LDH raised significantly over control in exposed group and improvement was noticed in glutathione treated group. Thus, the increased level of LDH in the current study may be associated with the increased tissue damage due to exposure (Ozgur et al., 2014). Improvement which occurred in the treated group can be attributed to the protective effect of glutathione enhancer on LDH activity which can remove free radicals developed by EMF (Reiter, 1994). Results are in agreement with those of Vojisavljevic et al. (2007) who studied the effect of electromagnetic radiation $(550-850 \mathrm{~nm})$ on 1-lactate dehydrogenase kinetic and he found increased activity of the enzyme.

EMF appeared to decrease significantly the RBC's in exposed group in comparison with the control and treated groups. This fact can be explained by the effect of EMR on the haematopoietic system which is susceptible to be damaged by radiation and that the high mitotic activity of the bone marrow make it the most vulnerable organ system to the effect of radiation (Marzook, 2006 and Fathi et al., 2014). Improvement noticed in treated group could be attributed to protective effect of antioxidants against oxidative damage of cells by free radicals and by preventing the oxidation of polyunsaturated fatty acids in the cell membrane. Results are in agreement with those of Heikinen et al. (2001), Nageswari (2003), Mukewar and Baile (2003) and El Abiad et al. (2007). Also, mean value of $\mathrm{Hb}$ concentration was significantly decreased in all exposed groups as compared to the control group which are consistent with those of Nageswari (2003), Mukewar and Baile (2003) and Ali et al. (2003). The antioxidant activity of glutathion and its protective effect on blood parameters was evident in this study and agreed with the study of El-Abiad et al. (2007) and El-Shafey et al. (2009). Results are in disagreement with Heikinen et al. (2001) who found increased hemoglobiin concentration in groups of rats exposed to EMR.

Also data showed that mean values of reticulocytes count was significantly increased in exposed group as compared to control and treated groups. The present results suggest that increased reticulocytes count may be due to physically induced haemolytic anaemia by the effect of chronic exposure to the EMF. Haemolytic disorders may be caused by many factors including physical agents (John, 1994). The haemolytic anaemia results primarily from increased

Egypt. J. Rad. Sci. Applic., Vol. 29, No. 1-2 (2016) 
red cell destruction (Brain, 1994) which stimulates erythropoiesis. The evaluation of suspected haemolytic states should include measures of increased red cell destruction and parameters of accelerated erythropoiesis which is measured by the reticulocyte count. Results are consistent with those of Germann (2004) and El Abiad et al. (2007). These results could be explained on the base of EMR exposure may be responsible for the changes of blood and glutathione enhancer can provide protection against the effect of EMR of MBS.

The present study revealed negligible changes in total leucocytes due to exposure. These results are in accordance with the finding of Tuschl et al. (1999) and Germann (2004) who studied the effect of high frequency radiation on persons exposed to GSM mobile phones. Also data are consistent with those of Marzook (2008) who found insignificant difference in leucocyte counts in a group of rats exposed to EMR radiation of bas station of frequency of 900930MHz Data disagree with those of Goldoni (1990) who found decreased leucocytes and platelets counts in group of men occupationally exposed to pulsed MW. Meanwhile, study of Svedenstal and Holmberg (1993) found that total leucocytes count was elevated in pulsed electromagnetic field exposed animals (CBA mice) compared to non-exposed control. This variation can be attributed to the differences in the frequency of EMF used and/ or duration and time of exposure, the mitotic rate of the exposed cell population and the differences in animal species used (Vinodha and Raghavan, 2015).

In conclusion, the current study indicates that glutathione enhancer as a potent antioxidant provide a great defines mechanism in EMR exposed animals.

\section{References}

Adey, W. R. (1981) Tissue interactions with nonionizing electromagnetic fields. Physiol. Rev., 61, 435.

Ahmedpoor, P., Efteckhar, E., Nourooz-Zadeh, J., Servat, H., Makhadoomi, K. and Ghafri, A. (2009) Glutathione, glutathione-related enzymes, and total antioxidant capacity in patients on maintenance dialysis. Iran. J. Kidney Dis., 3, 22.

Akdag, M., Dasdag, S., Cakir, D., Yokus, B., Kizil, G. and Kizil, M. (2013) Do 100and 500- $\mu$ T ELF magnetic fields alter beta-amyloid protein, protein carbonyl and malondialdehyde in rat brains? Electromagn. Biol. Med., 32, 363.

Alfred, E. H. (1994) Nitrogen metabolites and renal function. In: Clinical laboratory Medicine. Kenneth D. McChatchey (ed.) USA, Chapter 16, pp. 379-380.

Egypt. J. Rad. Sci. Applic., Vol. 29, No. 1-2 (2016) 
Ali, F. M., Mohamed, S. W. and Mohamed, M. R. (2003) Effect of $50 \mathrm{~Hz}, 0.2 \mathrm{mT}$ magnetic fields on $\mathrm{RBC}$ properties and heart functions of albino rats. Bioelecromagnetics, 24, 5355.

Ames, B. N., Catheart, R., Schwiers, E. and Hochstein. P. (1981) Uric acid provides an antioxidant defense in humans against oxidant and radical-caused aging and cancer: a hypothesis. Proc. Natl. Acad. Sci., 78, 6858.

Bergamaschi, A., Magrini, A., Ales, G., Coppetta, L. and Somma, G. (2004) Are thyroid dysfunctions related to stress or microwave exposure $(900 \mathrm{MHz})$ ? Int. J. Immunopathol. Pharmacol., 17, 31.

Bortkiewicz, A. (2001) A study on the biological effects of exposure mobile-phone frequency EMF. Med. Pr., 52, 101.

Brain, D. D. (1994) Red Blood Disorders. Clinical laboratory Medicine. Kenneth D. McClatchey (ed.), USA, Chapter 35, p. 865.

Brovkovich, V. M., Kurilo, N. B. and Baisphol, V. L. (1991) Action of millimeterrange electromagnetic radiation on the Ca pump of sarcoplasmic reticulum. Radiobiologiia, 31, 268.

CSIRO "Commonwealth Scientific and Industrial Research Organization Report" (1994) The Cell Membrane, Ion Exchange and Cellular effects of EMR. In: Status of Research on Biological Effects and Safety of Electromagnetic Radiation Telecommunication Frequencies. June, 1994.

Dasdag, S., Balci, K., Ayyildiz, M. O., Çelik, M. S., Tekes, S. and Kaplan, A. (1999) Blood biochemical parameters of the radio-link station workers. East. J. Med., 4, 10.

Djeridane, Y., Touitou, Y. and de Seze, R. (2008) Influence of EMF by GSM-900 cellular telephones on the circadian patterns of gonadal adrenal and pituitary hormones in men. Radiat. Res., 169, 337.

Draper, H. and Hadley, M. (1991) Malondialdehyde determination as index of lipid peroxidation. In: Methods in Enzymology. Edited by Pracker L, Glazer A., New York, Academic Press, 186, pp. 421-443.

Dumanskiı̆, Iu. D., Popovich, V. M. and Prokhvatilo, E. V. (1976) Hygienic evaluation of the electromagnetic field created by high-voltage electric power transmission lines. Gig. Sanit., 8, 19.

Dutta, J., Sharma, D. and Saxena, R. (2105) Oxidative stress mediated electrolyte imbalance in 30 known cases of knee osteoarthritis patients: A clinical approach. Asian J. Med. Sci., 6, 26.

El-Abiad, N. M, El-Aragi, G. M. and Marzook, E. A. (2007) Changes in some hematological parameters and thyroid hormones in rats exposed to pulsed electromagnetic field. Arab. J. Nucl. Sci. Appl., 40, 269. 
El-Abiad, N. M. (2002) Influence of pineal hormone on serum estradiol, catecholamines and lipid fractions in female rats exposed toelectromagnetic radiation of base station for cellular phone. Egypt. J. Applc. Sci., 17, 405.

El-Shafey, A. A., Ali, E. A. and Marzook, E. A. (2009) Effect of garlic oil on hematological parameters, blood respiration functions and serum testosterone in male rats exposed to electromagnetic field. Isotop. Rad. Res., 41, 397.

Fathi, E. and Farahzadi, F. (2014) Interaction of mobile telephone radiation with biological systems in veterinary and medicine. J. Biomed. Engin. Tech., 2, 1.

Fossati, P., Prencipe, L. and Berti, G. (1980) Use of 3,5-dichloro-2hydroxybenzensulfonic acid/4-aminophenazone chromogenic system in direct enzymatic assay of uric acid in serum and urine. Clin. Chem., 26, 227.

Friedman and Young (2001) Effects of disease on clinical laboratory tests. $4^{\text {th }}$ ed, vol 1, AACC Press, Washington, RSA.

Germann, P. (2004) Study of the influence of pulsed electromagnetic radiation on blood. Red blood cells lump by mobile phone. In Independent Media Center (Database on line). USA, 2004, Available from http://www.new.medical.net.

Goldoni, J. (1990) Haematological change in peripheral blood of workers occupationally exposed microwave radiation, Health Phys., 58, 205.

Goodman, E. M., Greenebaum, B. and Marron, M. T. (1995) Effects of electromagnetic fields on molecules and cells. Int. Rev. Cytoly., 158, 279.

Guyatt, G. H., Oxman, A. D., Ali, M., Willian, A., Mcllory, W. and Patterson, C. J. (1992) Laboratory diagnosis of iron-deficiency anemia: an overview. J. Gen. Intern. Med., 7, 145.

Halliwell, B. (1999) Antioxidant defense mechanisms: from the beginning to the end. Free Radic. Biol. Med., 31, 261.

Hamed, S. A., Abdellah, M. M. and El-Melegy, N, (2004) Blood levels of trace elements, electrolytes, and oxidative stress/antioxidant systems in epileptic patients. J. Pjarmacol. Sci., 96, 465.

Hashem, M. A. 1. and El-Sharkawy, N. I. (2009) The effects of low electromagnetic field and lead acetate combination on some hemato-biochemical and immunotoxicological parameters in mice. Turk. J. Hematol., 26, 181.

Hata, K., Yamaguchi, H., Tsurita, G., Watanabe, S., Wake, K., Taki, M., Ueno, S. and Nagawa, H. (2005) Short term exposure to $1439 \mathrm{MHz}$ pulsed TDMA field does not alter melatonin synthesis in rats. Bioelectromagnetics, 26, 49.

Heikkinen, P., Kosma, V. M., Hongisto, T., Huuskonen, H., Hyysalo, P., Komulainen, H., Kumlin, T., Lahtinen, T., Lang, D., Puranen, L. and Juutilainen, J. (2001) Effects of mobile phone radiation on X-ray-induced tumorigenesis in mice. Radiat. Res., 156, 775.

Egypt. J. Rad. Sci. Applic., Vol. 29, No. 1-2 (2016) 
Ilhan, A., Gurel, A., Armutcu, F., Kamisli, S., Iraz, M., Akyol, O and Ozen, S. (2004) Ginko biloba prevents mobile phone-induced oxidative stressin rat brain. Clin. Chim. Acta, 340, 153.

Johanson, O. (2009) Disturbance of the immune system by electromagnetic field $-\mathrm{A}$ potentially underlying cause for cellular damage and tissue repair reduction which could lead to disease and impairment. Pathophsiology, 16, 157.

John, T. B. (1994) Clinical Laboratory Medicine. Kenneth D.McChatchey (ed.), Chapter 41, USA, p. 1063.

Kesari, K. K., Siddiqui, M. H., Meena, R., Verma, H. N. and Kumar, S. (2013) Cell phone radiation exposure on brain and associated biological systems. Indian J. Exp. Biol., 51, 187.

Koyu, A., Cesur, G., Ozguner, F., Akdogan, M., Mollaoglu, H. and Ozen, S. (2005) Effects of $900 \mathrm{MHz}$ electromagnetic field on TSH and thyroid hormones in rats. Toxicol. Lett., 157, 257.

Levis, A., Masiero, L., Orio, P., Biggin, S. and Garbisa, S. (2015) Health Effects of Mobile Phone Usage. In: Z.Yan (Ed.), Encyclopedia of Mobile Phone Behavior. Information Science Reference. Hershey PA, USA, pp. 607-629.

Maganioti, A., Hountala, C. D., Papageorgiou, C. C., Kyprianou, M. A., Rabavilas, A. D. and Capsalis, C. N. (2010) Principal component analysis of the P600 waveform: RF and gender effects. Neurosci Lett., 478, 19.

Marzook, E. A. (2006) Effect of pulsed electromagnetic field on some biochemical and hematological parameters of female rats. Isotope Rad. Res., 38, 1245.

Marzook, E. A. (2008) Protective role of antioxidants against oxidative stress and biological changes induced by exposure of rats to mobile base station. Sci. Med. J., 20, 1.

Matamoros, M. A., Dalton, D. A., Ramos, J., Clemente, M. R., Rubio, M. C. and Becana, M. (2003) Biochemistry and molecular biology of antioxidants in the rhizobia-legumesymbosis. Plant Physiol., 133, 499.

Moustafa, Y. M., Moustafa, R. M., Belacy, A., Abou-El-Ela, S. H. and Ali, F. M. (2001) Effects of acute exposure to the radiofrequency fields of cellular phones on plasma lipid peroxide and antioxidant activities in human erythrocytes. J. Pharm. Anal., 26, 605.

Mukewar, M. and Baile, V. (2003) Effect of electric fields on the blood of rat-sprague dawley. J. Bioelectromag. Med., 8, 1 .

Nageswari, K. S. (2003) Biological effects of microwaves and mobile telephony. Proceeding of the International Conference on Nonionizing Radiation. India ICNIR. Electromagnetic Field and Our Health, 1-11.

Egypt. J. Rad. Sci. Applic., Vol. 29, No. 1-2 (2016) 
Oktem, F., Ozguner, F., Mollaoglu, H., Koyu, A. and Uz, E. (2004) Oxidative damage in the kidney induced by $900-\mathrm{MHz}$-emitted mobile phone: protection by melatonin. Arch. Med. Res., 36, 3505.

Ozguner, F., Altinbas, A., Ozaydin, M., Dogan, A., Vural, H., Kisioglu, A. N., Cesur, G. and Yildirim, N. G. (2005) Mobile phone-induced myocardial oxidative stress: protection by a novel antioxidant agent caffeic acid phenethyl ester. Toxicol. Ind. Health, 21, 223.

Ozguner, F., Bardak, Y. and Comlekci, S. (2006) Protective effects of melatonin and caffeic acid phenethyl ester against retinal oxidative stress in long-term use of mobile phone: a comparative study. Mol. Cell Biochem., 282, 83.

Ozgur, E., Guler, G., Kismali, G. and Seyhan, N. (2014) Mobile phone radiation alters proliferation of hepatocarcinoma cells. Cell biochem biophys., 70, 983.

Persson, P. Hakanson, R. Axelson, J. and Sundier, F. (1989) Gastrin releases a blood calcium-lowering peptide from the acid-producing part of the rat stomach. Proc. Nat. Acad. Sci., 86, 2834.

Reiter, R. J. (1994) Melatonin suppression by static and extremely low frequency electromagnetic fields: relationship to the reported increased incidence of cancer. Rev. Environ. Health, 10, 171.

Schwarz, C., Leichtle, A., Arampatzis, S., Fiedler, G. M., Zimmermann, H., Exadaktylos, A. K. and Lindner, G. (2012) Thyroid function and serum electrolytes: does an association really exist? Swiss Med. Wkly, 142, w13669.

Sooes, M., Taylor, S. I., Gardt, T. and Siddle, K. (1984) A rapid, sensitive two-site immunoradiometric assay for TSH using monoclonal antibodies, investigations of factors affecting optimization. J. Immunol. Methods, 73, 237.

Stopczyk, D., Gnitecki, W., Buczynski, A., Markuszewski, L. and Buczyński, J. (2002) Effect of electromagnetic field produced by mobile phones on the activity of superoxide dismutase(SOD-1) and the level of malondialdehyde (MDA) in vitro study. Med Pr., 53, 311.

Svedenstal, B. M. and Holmberg, B. (1993) Lymphoma development among mice exposed to X-rays and pulsed magnetic fields. Int. J, Radiat. Biol., 64, 119.

Tietz, N. W. (1970) Fundamentals of Clinical Chemistry. W.B.Saunders, Phildelphia, pp 449-453.

Tuschl, H., Neubauer, G., Garn, H. Duftschmid, K., Winker, N. and Brusl, H. (1999) Occupational exposure to high frequency electromagnetic fields and its effect on human immune parameters. Int. J. Occup. Med. Environ. Health, 12, 239.

Vinodha, E. and Raghavan, S. (2015) Possible effects of cell phone radiation: An overview paper. In Electronics and Communication Systems (ICECS), 2015 $2^{\text {nd }}$ International Conference on Electronics and Communication, pp. 837-841.

Egypt. J. Rad. Sci. Applic., Vol. 29, No. 1-2 (2016) 
Vojisavljevic, V., Pirogova, E. and Cosic, I. (2007) Influence of electromagnetic radiation on enzyme kinetics. Conf. Proc. IEEE Eng. Med. Biol. Soc., 2007, 5021.

Witt, I. and Trendlenberg, C. (1982) Joint study to establish reference values for clinical chemical parameters in childhood. J. Clin. Chem. Clin. Biochem., 20, 235.

Yakymenko, I., Tsybullin, O., Sidorik, E., Henshel, D., Kyrylenko, O. and Kyrylenko, S. (2016) Oxidative mechanisms of biological activity of lowintensity radiofrequency radiation. Electromagn. Biol. Med., 35, 186.

Yurekli, A. L., Ozkan, M., Kalkan, T., Saybasili, H., Tuncel, H., Atukeren, P., Gumustas, K., Seker, S. and Kalkan, T. (2006) GSM base station electromagnetic radiation and oxidative stress in rats. Electromagn. Biol. Med., 25, 177.

(Received: 10/11/2016;

accepted: 04/12/2016) 


\title{
الجلوتاثيون المحفز يقى بعض المعاييز الكيموحيوية و الامويـة من تأثير المجال الكهرومغناطيسيي العيدي
}

\author{
إبتسام عبد المجيد مرزوق ، و فوزي عبد المجيد مرزوقة

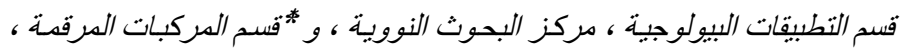

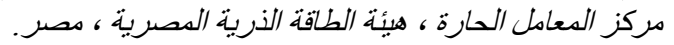

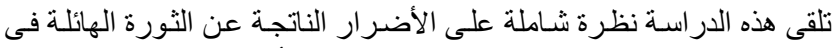

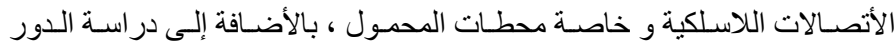

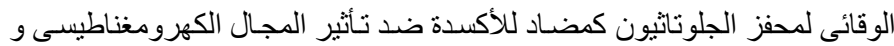

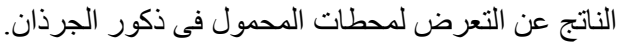

لذلك تمت در اسة تأثير الموجات الكهرومغناطيسية على كلا من إنزيم لاكتيت

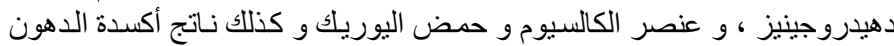

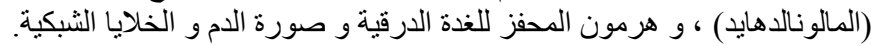

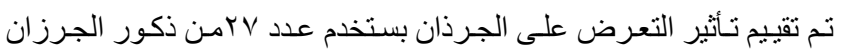

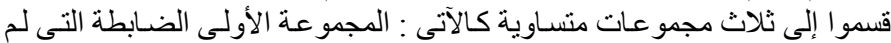

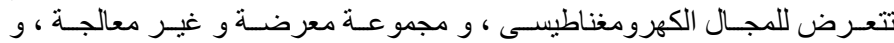

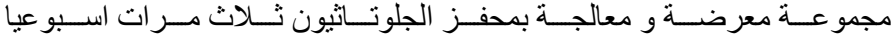

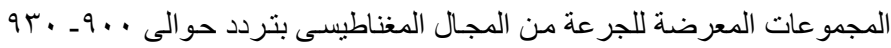

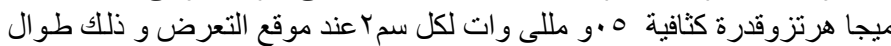

اليوم لمدة ثمانية اسابيع.

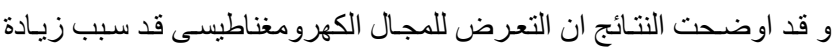

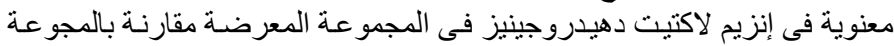

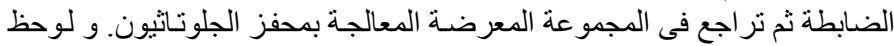

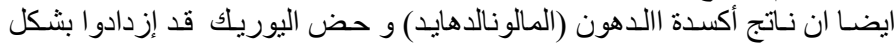

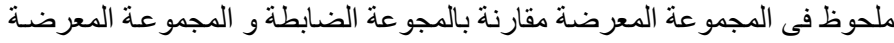

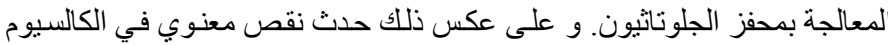

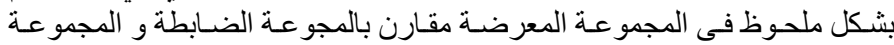

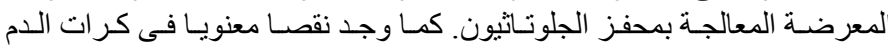

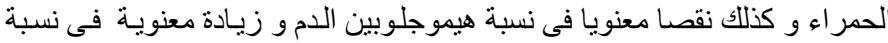

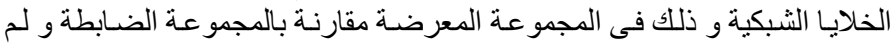

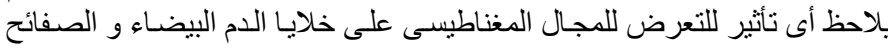

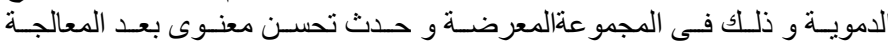
بالجلوتاثيون.

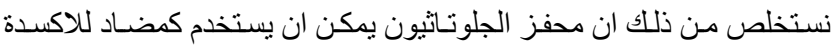

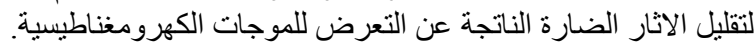

Egypt. J. Rad. Sci. Applic., Vol. 29, No. 1-2 (2016) 